\title{
ROD-CORED VESICLES IN LARGE GRANULAR LYMPHOCYTE (LGL) LEUKEMIA CELLS OF RATS: ALTERATIONS INDUCED FOLLOWING METASTASIS TO THE LIVER
}

\author{
Kenji Kaneda ${ }^{1,4}$, Thomas J. Sayers ${ }^{1}$, Theresa A. Wiltrout ${ }^{1}$, Anne M. Pilaro ${ }^{1}$, Akiko Kojima ${ }^{4}$, \\ Kunio Nagashima ${ }^{3}$, Matthew A. Gonda ${ }^{3}$, Jerrold M. Ward ${ }^{2}$, Craig W. Reynolds ${ }^{1}$, John R. \\ OrTALDO $^{1}$ and RoBert H. Wiltrout ${ }^{1}$ \\ ${ }^{1}$ Laboratory of Experimental Immunology, Biological Resources Branch, Biological Response Modifiers Program, ${ }^{2}$ Veterinary \\ \& Tumor Pathology Section, Office of Laboratory Animal Science, Biological Carcinogenesis and Development Program, \\ ${ }^{3}$ Laboratory of Cell and Molecular Structure, Program Resources/DynCorp Inc., NCI-FCRDC, Frederick, MD 21702--1201, \\ U.S.A., and ${ }^{4}$ Department of Anatomy, Osaka City University Medical School, Osaka 545, Japan
}

\begin{abstract}
Rat transplantable large granular lymphocyte (LGL) tumor lines, termed RNK cells, have been used for the analysis of dense granules. It also has been reported that LGL from normal rats have rod-cored vesicles (RCV), which are considered to be a marker of NK cell maturation. There have been, however, no reports on the presence of RCV in RNK cells. All RNK cell lines examined here possessed RCV, although RNK-11 cells contained more empty $0.2 \mu \mathrm{m}$ vesicles and RCV than did RNK-16 and -7 cells. The high expression of vesicles of RNK-11 cells was maintained during several in vivo passages. RNK-16 and RNK-0 cells after rapid or delayed metastasis, respectively, exhibited more empty $0.2 \mu \mathrm{m}$ vesicles and RCV than those that metastasized to the spleen. There was, however, no significant difference in the number of dense granules between RNK cells in these two organs. The present study has revealed that RCV are maintained after the transformation of NK cells to tumorigenic RNK cells and that the expression of RCV in RNK cells is augmented by the liver microenvironment. Therefore, RNK cells will serve as a useful model for the analysis of biochemical and functional properties of RCV.
\end{abstract}

Large granular lymphocyte (LGL) leukemia spontaneously occurs in aged F344 rats (24-34 months) and becomes a major cause of death. These

Correspondence should be sent to: Robert H. Wiltrout, Laboratory of Experimental Immunology, Biological Response Modifiers Program, NCI-FCRDC, Frederick, MD 21702-1201, U.S.A.

The content of this publication does not necessarily reflect the views or policies of the Department of Health and Human Services, nor does mention of trade names, commercial products, or organizations imply endorsement by the U.S. Government. Animal care was provided in accordance with the procedures outlined in the 'Guide for the care and use of Laboratory Animals' (NIH publication No. 86-23, 1985). leukemia cells infiltrate into various organs including spleen, liver and lungs and exert natural killer (NK)-mediated cytotoxicity in vitro (14). Seventeen transplantable LGL leukemia cell lines, designated rat natural killer (RNK)-0 to -16 cells, have been established from the primary rat LGL leukemias $(9,14)$. They are LGL in origin and have morphological, phenotypical and functional characteristics similar to those of normal rat LGL, although they are tumorigenic in vivo. Specifically, RNK cells contain dense granules in the cytoplasm, express several NK cell surface markers and mediate NK activity as well as antibody-dependent cellular cytotoxicity (ADCC) (9). Since RNK cells may be obtained in high purity $(>90 \%)$ and in large numbers (more than $1 \times 10^{10}$ cells per animal) after 
intraperitoneal (i.p.) inoculation, they have been useful as a model for studies of NK cell biology. They have been particularly useful for the biochemical and immunohistological analyses of dense granules, which have revealed that these structures contain characteristic substances such as perforin and serine esterase that are important in NK-mediated cytolysis $(1,3,8,10)$.

In addition to dense granules, there is another characteristic cell organelle, rod-cored vesicles (RCV), exhibited by LGL. The RCV are $0.17-0.2$ $\mu \mathrm{m}$ in diameter and contain one rod-structure (6, 7). RCV are thought to participate in NK cellmediated cytolytic function because they increase in number when NK activity is augmented (2) and often localize preferentially in the contact area between LGL and bound target cells (4). In addition to RCV, LGL contain 'empty' vesicles with the same diameter as RCV (7). These two types of vesicles are thought to be closely related and are therefore collectively termed $0.2 \mu \mathrm{m}$ vesicles (4). The biochemical nature of the contents of RCV remains unknown. Although RCV are observed in several animal species, rat NK cells contain the greatest number, so analysis of RCV have been mostly performed in this species. Thus, RNK cells, which are of rat origin, are a good source of material for the study of RCV.

Recently, liver-associated NK cells, which are also termed pit cells $(7,16)$, have been considered to be a more differentiated form of peripheral LGL because there are several morphological and functional differences between LGL isolated from the liver vs the spleen or peripheral blood (13). We reported that liver NK cells express a greater number of empty $0.2 \mu \mathrm{m}$ vesicles and RCV than do splenic or peripheral blood NK cells in the normal rat (5). Taken together these data suggest that the degree of expression of these vesicles could be a useful indicator of the maturation or differentiation state of LGL, and/or that the expression of this unique structure may be up-regulated preferentially by the liver microenvironment (5).

In order to investigate the NK cell lineagespecific character of RCV, we examined the expression and frequency of RCV in three in vivo passaged RNK cell lines (RNK-7, -11 and -16) under an electron microscope. Furthermore, for the purpose of investigating if expression of RCV by RNK cells was differentially modulated in various anatomical sites following rapid or delayed metastasis to various organs, we quantitatively determined the frequency of RCV and dense granules in metastasizing RNK cells by electron microscopy and compared among RNK cells in different anatomical sites.

\section{MATERIALS AND METHODS}

\section{Animals}

Specific pathogen-free Fischer [F344/NCr] rats (male, 6-8 weeks old) were obtained from the Animal Production Area, NCI-Frederick Cancer Research and Development Center, Frederick, MD.

\section{Cell Lines}

Three RNK cell lines, RNK-7, -11 and -16, which were maintained at NCI-FCRDC, were used after several in vivo i.p. passages of $1 \times 10^{7}$ RNK cells into the pristane-primed F344 rats. Two weeks later, the ascites was aspirated and washed twice with phosphate buffer, $\mathrm{pH} 7.4$. RNK-0 cells have been stored in the frozen state at NCI-FCRDC.

\section{Experimental Metastasis}

We injected $1 \times 10^{7}$ RNK-16 cells or $5 \times 10^{6}$ RNK-0 cells i.p. into two pristane-unprimed F344 rats and two primed rats respectively. Eighteen days later, in vivo passaged RNK-16 cells gave rise to metastasis in the spleen and liver with development of ascites. These organs became swollen due to the massive infiltration of leukemia cells. Conversely, i.p. inoculation of a frozen stock of RNK-0 cells induced no symptoms at 18 days, but resulted in progressive weight loss and pale mucous membrane with the occurrence of tumor metastasis in various organs at 3 months after administration. The liver and spleen were enlarged as well. There was, however, only a small amount of ascites.

\section{Electron Microscopy}

The cell suspensions of RNK cells which were harvested from the peritoneal cavity were mixed with an equal volume of $3 \%$ glutaraldehyde in $0.067 \mathrm{M}$ cacodylate buffer, $\mathrm{pH} 7.4$, plus $1 \%$ sucrose for 20 $\min$ at room temperature. The cells were then centrifuged at 1,500 rpm for $10 \mathrm{~min}$.

For the preparation of tissue, rats were anesthetized by i.p. injection of sodium pentobarbital. The liver was perfused via a portal vein first with saline for $40 \mathrm{~s}$ and then with $1.5 \%$ glutaraldehyde in $0.067 \mathrm{M}$ cacodylate buffer, $\mathrm{pH} .7 .4$, plus $1 \%$ sucrose for $2 \mathrm{~min}$. The spleen was cut into three 
pieces and fixed by injecting the same fixative into the blood vessels at the hilus. The liver and the spleen were then cut into small blocks. For rats injected with RNK-0 cells, the liver and spleen were fixed in the same way. Other organs, i.e., lungs, kidneys and lymph nodes, were also removed. Lungs were fixed by intratracheal infusion of the fixative, kidneys were fixed by injecting the fixative into the blood vessels at the hilus and lymph nodes were immersed in the fixative after cutting into small blocks.

The fixed material of the cell pellet and small tissue blocks were post-fixed with $1 \% \mathrm{OsO}_{4}$ in 0.1 $\mathrm{M}$ phosphate buffer, $\mathrm{pH} 7.4$, dehydrated in ethanol series and embedded in epoxy resin (LX-112, Ladd Res., U.S.A.). Thin sections were stained with uranyl acetate and lead citrate and observed under an $\mathrm{H}-7000$ electron microscope (Hitachi, Japan) or a JEM-1200EX electron microscope (JEOL, Japan) at $100 \mathrm{kV}$.

\section{Quantitative Analysis}

We counted the number of $0.2 \mu \mathrm{m}$ vesicles, $\mathrm{RCV}$ and dense granules in the RNK cells on the screen of an electron microscope or on the photographs at magnification of more than $20,000 \times$. We counted vesicles and granules only in sections of RNK cells that showed Golgi apparatus or centrioles (5), because the vesicles and granules are frequent at the central part of the cell.

Significant differences between the two populations were analyzed by unpaired Student's $t$-test.

\section{RESULTS}

\section{Analysis of RNK Cell Ultrastructure after Growth in the Peritoneal Cavity}

The in vivo-passaged RNK-7, -11 and -16 cells were morphologically distinct from normal LGL; they were larger in size (about $10 \mu \mathrm{m}$ in diameter), rich in cell organelles such as mitochondria and polysomes, and the nucleus generally exhibited an irregular contour (Figs. 1 and 2). All of these RNK cell lines contained dense granules (Fig. 1), multivesicular bodies (MVB) (Fig. 2A) and the intermediate morphological structures between dense granules and MVB (Fig. 3, A and B) similar to those of normal NK cells. They also possessed $0.2 \mu \mathrm{m}$ vesicles which contained a rod-cored structure (RCV) and 'empty' $0.2 \mu \mathrm{m}$ vesicles with no visible rod on the section (Fig. 3).

There was, however, a difference in frequency of RCV and in the size of dense granules among RNK cell lines. RNK-11 cells had about 2-fold more empty $0.2 \mu \mathrm{m}$ vesicles and 3-fold more $\mathrm{RCV}$ and exhibited smaller sized granules than RNK-16 cells (Table 1; Fig. 2, A and B), while RNK-7 cells showed similar features to RNK-16 cells. The higher frequency of vesicles in RNK-11 cells remained constant even after several in vivo passages (Table 2).

\section{Analysis of RNK Cell Ultrastructure after Metastasis to the Spleen and Liver}

By 18 days after the i.p. injection of tumor cells into unprimed rats, RNK-16 cells had metastasized to the spleen and liver. The spleen was enlarged to 3-4 times its normal size in volume and the liver was also enlarged. In these tissues, RNK cells were differentiated morphologically from resident LGL by their larger cell size (about $10 \mu \mathrm{m}$ in diameter), irregular nuclear contour and abundance of cell organelles (polysomes and mitochondria). There were many RNK cells occupying a major part of the red pulp of the spleen (Fig. 4). They were usually round and closely packed. They contained dense granules and $0.2 \mu \mathrm{m}$ vesicles in the cytoplasm (Fig. 5). In the liver, RNK cells infiltrated diffusely in the liver lobule and were found both in the sinusoid and in the space of Disse, attaching to sinusoidal endothelial cells and Kupffer cells (Figs. 6 and 7).

There were more $0.2 \mu \mathrm{m}$ vesicles and $\mathrm{RCV}$ in the RNK-16 cells that were localized in the liver (Fig. 7), compared to those in the spleen (Fig. 5). For example, liver RNK cells contained significantly more $(P<0.01) \quad 0.2 \mu \mathrm{m}$ vesicles $(8.1)$ and RCV (1.4) per cell section on the average than did splenic or peritoneal RNK cells, which had 3.1 0.2 $\mu \mathrm{m}$ vesicles and $0.5 \mathrm{RCV}$ and $4.20 .2 \mu \mathrm{m}$ vesicles and $0.7 \mathrm{RCV}$, respectively (Table 3 ). There was no significant difference in the number of $0.2 \mu \mathrm{m}$ vesicles between splenic and peritoneal RNK cells. The frequency of RNK cells with more than eight $0.2 \mu \mathrm{m}$ vesicles per cell section was $53 \%$ in the liver, $3 \%$ in the spleen and $9 \%$ in the peritoneum. The number of RNK cells with more than three RCV per cell section was about $20 \%$ in the liver, while it was only $1-2 \%$ in the spleen and peritoneum (Fig. 8). On the other hand, liver RNK cells exhibited only a slight increase $(P<0.05)$ in the number of dense granules, compared to peritoneal RNK cells, with no significant difference in the size of granules $(0.42 \pm 0.07 \mu \mathrm{m}$ in diameter in 


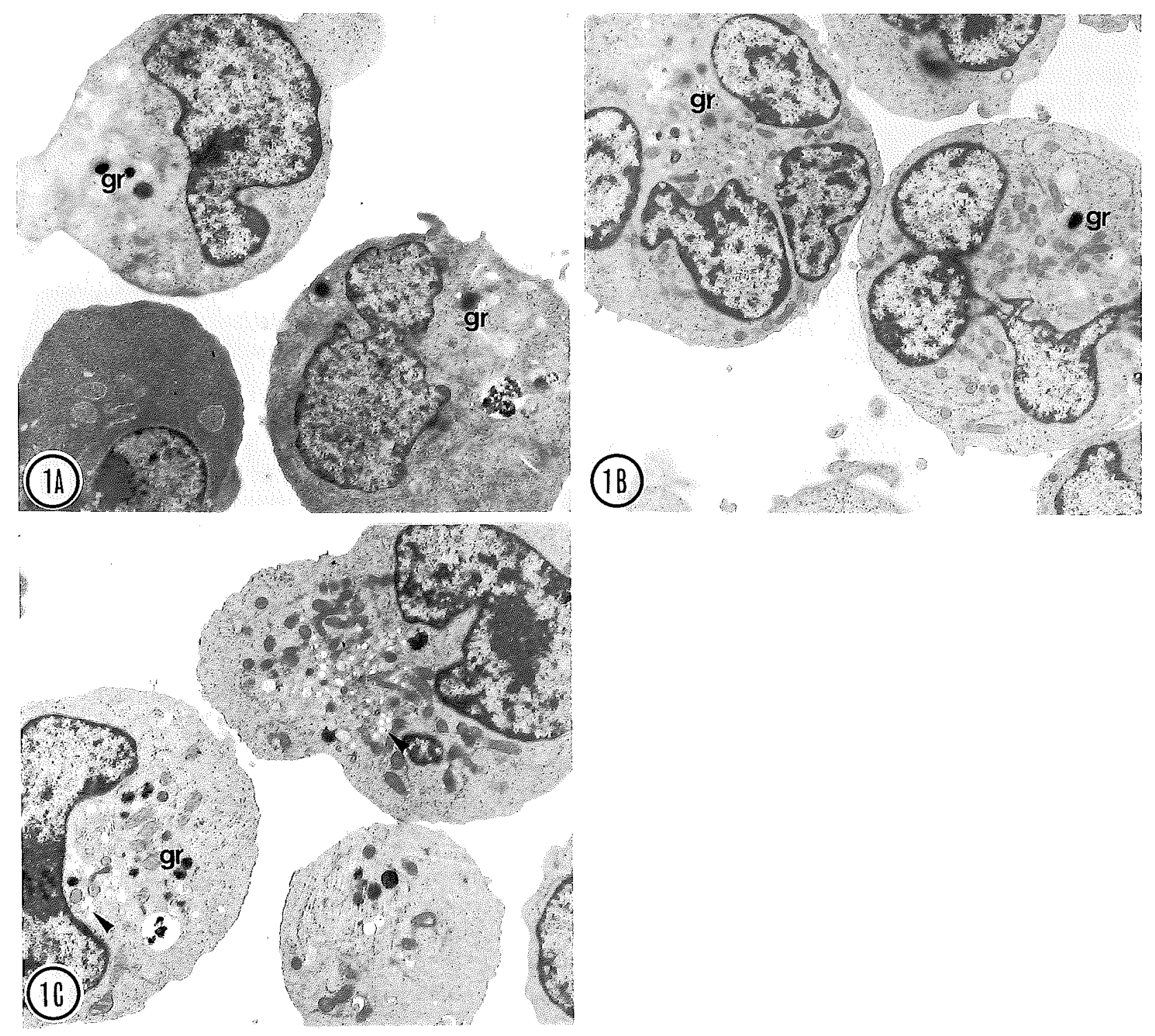

Fig. 1 Ultrastructural characteristics of intraperitoneally passaged RNK cells. The RNK cell lines RNK-7 (passage 15) (A), RNK-16 (passage 8) (B) and RNK-11 (passage 3) (C) all show the morphology of LGL. There are a small number of large sized dense granules $(g r)$ in RNK-7 cells and RNK-16 cells, while RNK-11 cells have many, relatively small-sized granules. Many $0.2 \mu \mathrm{m}$-vesicles (arrowheads) are also expressed in RNK-11 cells. A, $\times 6,100$; $\mathrm{B}, \times 5,600 ; \mathrm{C}, \times 5,600$

liver RNK cells $[\mathrm{n}=17]$ versus $0.37 \pm 0.11 \mu \mathrm{m}$ in splenic RNK cells $[n=10])$. These results demonstrate that the RNK cells that have metastasized to the liver exhibit a pronounced increase in $0.2 \mu \mathrm{m}$ vesicles and RCV.

Similar results as RNK-16 metastases were obtained in the experiment of the long-term metastasis of RNK- 0 cells. RNK- 0 cells that had been immediately recovered from the frozen state exhibited metastasis at 3 months after i.p. injection and animals showed prominent weight loss and anemia similar to the symptoms in RNK tumor transplantation recipient rats described by Ward and Reynolds (14). The reason for this slow metastasis of RNK-0 cells is unknown but may be related to their cytological characteristics; RNK-0 cells were rather similar to normal LGL in size (about $7 \mu \mathrm{m}$ in diameter) as previously reported (14) and in morphology as shown here. Many RNK-0 cells were found in various organs, sometimes gathering 

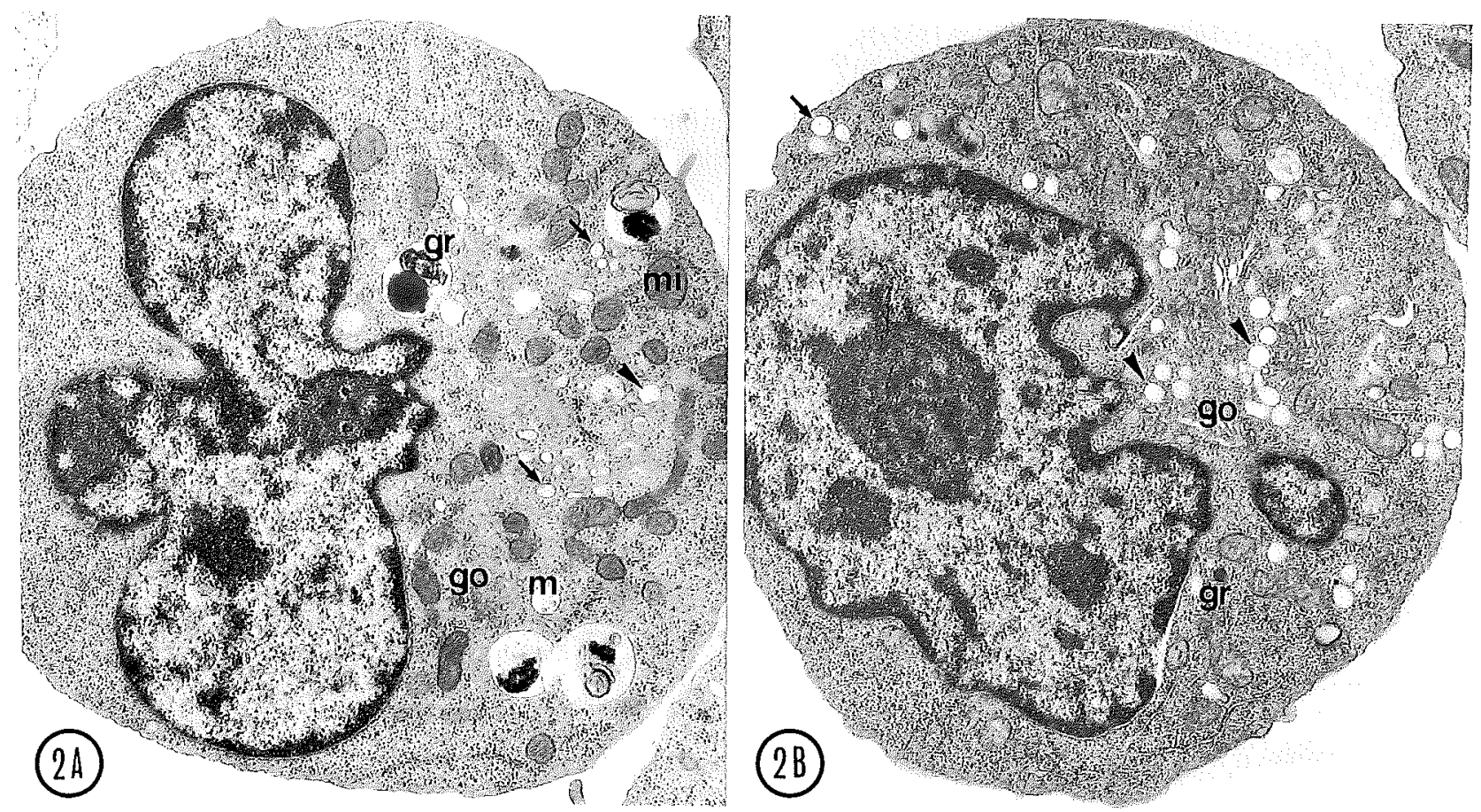

Fig. 2 Fine structure of RNK-16 cells and RNK-11 cells. The RNK cell lines RNK-16 (passage 8) (A) and RNK-11 (passage 3) (B) have pleiomorphic nuclei and are rich in polysomes and mitochondria (mi). RNK-16 cells have large dense granules $(g r)$ and a small number of RCV (arrows) and empty $0.2 \mu \mathrm{m}$ vesicles (arrowheads), while RNK-11 cells contain small granules ( $g r$ ) and many $0.2 \mu \mathrm{m}$ vesicles (arrowheads) and RCV (arrow). $m, \mathrm{MVB}$; go, Golgi apparatuses; A, $\times 11,000 ; \mathrm{B}, \times 11,000$
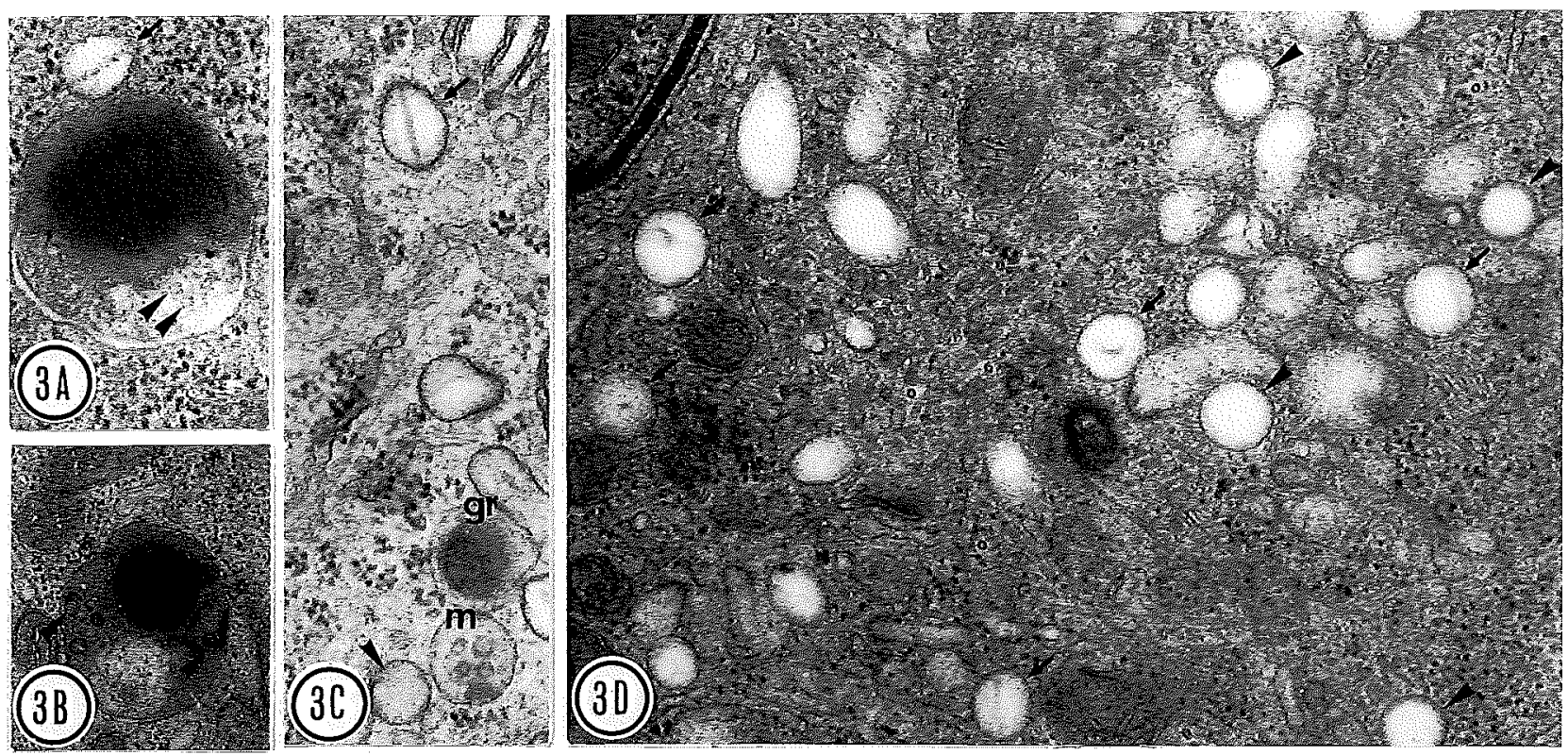

Fig. 3 Granule structure in RNK cells. A: An intermediate form of granules between dense granules and MVB can be seen, as well as RCV (arrow) in RNK-7 cells. Arrowheads indicate small vesicles in the granule. B: An intermediate form of granule in RNK-16 cells. Arrowheads indicate small vesicles in the granule. C: A dense granule ( $g r$ ), MVB $(\mathrm{m}), \mathrm{RCV}$ (arrow) and an empty $0.2 \mu \mathrm{m}$ vesicle (arrowhead) are visible in RNK-16 cells. D: Many RCV (arrows) and empty $0.2 \mu \mathrm{m}$ vesicles (arrowheads) are visible in RNK-11 cells. A, $\times 40,000 ; \mathrm{B}, \times 24,000 ; \mathrm{C}, \times 40,000 ; \mathrm{D}, \times 39,000$ 
Table 1 Frequency of $0.2 \mu \mathrm{m}$ Vesicles in RNK-16, -7 and -11 Cells Which Have Been Harvested from the Peritoneal Cavity of Pristane-Primed F344 Rats

\begin{tabular}{cccc}
\hline & \multicolumn{2}{c}{$0.2 \mu \mathrm{m}$ vesicles (number } \\
Cell lines & per cell transection $\pm \mathrm{SD})$ & \multicolumn{2}{c}{$\begin{array}{c}\text { Frequency of RCV- } \\
\text { containing RNK cells }\end{array}$} \\
& Total & RCV & $(\%)$ \\
\hline $\begin{array}{c}\text { RNK-11 (passage 2) } \\
(\mathrm{n}=51 \text { cells) }\end{array}$ & $8.8 \pm 5.3^{*}$ & $2.0 \pm 1.8^{*}$ & 75 \\
$\begin{array}{c}\text { RNK-16 (passage } 8) \\
(\mathrm{n}=49 \text { cells) }\end{array}$ & $4.2 \pm 3.2$ & $0.7 \pm 0.8$ & 47 \\
$\begin{array}{c}\text { RNK-7 (passage } 8) \\
(\mathrm{n}=31 \text { cells) }\end{array}$ & $3.6 \pm 2.7$ & $0.7 \pm 1.2$ & 42 \\
\hline
\end{tabular}

*Significantly greater than RNK-16 and RNK-7, $P<0.01$

Table 2 Frequency of $0.2 \mu \mathrm{m}$ Vesicles in RNK-11 Cells after in vivo Passage in the Peritoneal Cavity of Pristane-Primed F344 Rats

\begin{tabular}{cc}
\hline Passage number & $\begin{array}{c}0.2 \mu \mathrm{m} \text { vesicles } \\
\text { (number per cell transection } \pm \mathrm{SD} \text { ) }\end{array}$ \\
\hline $2(\mathrm{n}=23)$ & $8.8 \pm 6.2$ \\
$3(\mathrm{n}=26)$ & $11.6 \pm 6.0$ \\
$4(\mathrm{n}=23)$ & $9.5 \pm 6.2$ \\
\hline
\end{tabular}

No significant difference among the passages was observed.

in groups. In the liver, they were usually localized in the sinusoid and possessed many $0.2 \mu \mathrm{m}$ vesicles and RCV (Fig. 9). In the lungs, the RNK cells were usually localized in the capillaries (Fig. 10) and some had migrated into the connective tissue of the alveolar septum. In the spleen, they predominantly existed in the red pulp (Fig. 11). Splenic RNK cells sometimes showed abundant vesicles, but generally fewer than hepatic RNK cells. In the kidneys where normal LGL are usually not seen, RNK cells existed both inside and outside the capillaries of the tubules (Fig. 12). There was no morphological difference between intravascular and extravascular tumor cells. They were also frequent in the lymph nodes (data not shown). RNK cells in the latter three organs exhibited a small number of $0.2 \mu \mathrm{m}$ vesicles.

RNK- 0 cells exhibited the augmented expression of $0.2 \mu \mathrm{m}$ vesicles and RCV after metastasis to the liver, compared to RNK-0 cells in other organs (spleen, lungs, kidneys and lymph nodes) (Table 4). The frequency of $0.2 \mu \mathrm{m}$ vesicles and RCV in RNK-0 cells in the liver was $11.6 \pm 4.9$ and $2.1 \pm$ 1.6 respectively and that in the spleen was $4.9 \pm$ 4.0 and $0.9 \pm 1.4$ respectively; these values were similar to those in RNK-16 cells in the liver and spleen described above. There was, however, no significant difference in the number of dense granules among RNK- 0 cells in five organs. The diameter of dense granules in RNK-0 cells was $0.38 \pm$ $0.04 \mu \mathrm{m}$ in the liver $(\mathrm{n}=30), 0.37 \pm 0.04 \mu \mathrm{m}$ in the spleen $(\mathrm{n}=30), 0.34 \pm 0.08 \mu \mathrm{m}$ in the lungs ( $\mathrm{n}$ $=30), 0.31 \pm 0.04 \mu \mathrm{m}$ in the kidneys $(\mathrm{n}=30)$ and $0.31 \pm 0.03 \mu \mathrm{m}$ in the lymph nodes $(\mathrm{n}=30)$ with a significant difference $(P<0.01)$ observed between the liver and lymph nodes and between the liver and kidney.

\section{DISCUSSION}

Transplantable LGL leukemia cell lines, RNK-0 to -16 , established from primary rat LGL leukemias $(9,14)$ are LGL in origin and exert both NK and ADCC-mediated cytotoxicity, but differ slightly in morphology, phenotype and functional properties. Both RNK-11 and 16 cells are Thy $1.1^{+}$, which suggests relative immaturity, while RNK-7 cells are Thy $1.1^{-}$(9). Low levels of cytotoxicity in $4 \mathrm{~h}$ assays were detected in RNK-7 cells during the first two passages after transplantation, while RNK-11 and 16 cells were highly cytotoxic (9). By light microscopy, it has been reported that RNK-16 cells have obvious azurophilic granules, while RNK-11 cells contain few granules (14). However, present electron microscopic analysis reveals that RNK-11 cells do have dense granules, which are more frequent but smaller in size than those of RNK-16 cells. The morphological characteristics of the dense granules were similar among the three RNK lines in that they were routinely spherical and often showed an intermediate form between MVB and dense granules. These features are char- 


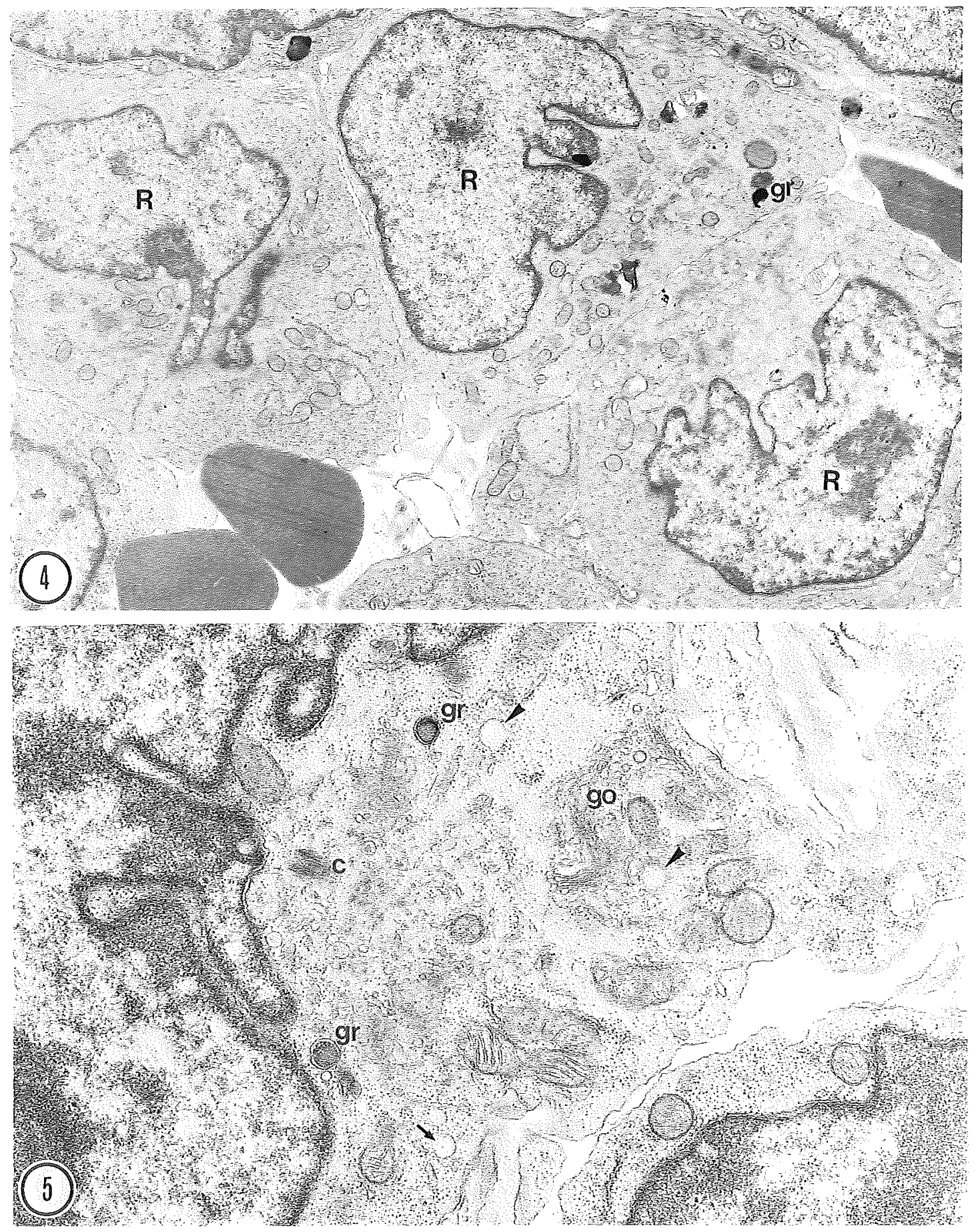

Fig. 4 Ultrastructure of RNK-16 cells (passage 7) found in the spleen 18 days after intraperitoneal injection. RNK-16 cells $(R)$ in the red pulp of the spleen have irregular shaped nuclei and small dense granules $(g r) . \times 6,900$

Fig. 5 Higher magnification of the cytoplasm of a metastasized RNK-16 cell in the spleen. A small number of dense granules $(\mathrm{gr})$ and $0.2 \mu \mathrm{m}$ vesicles, i.e., RCV (arrow) and empty vesicles (arrowheads), are seen. $\times 19,000$ 


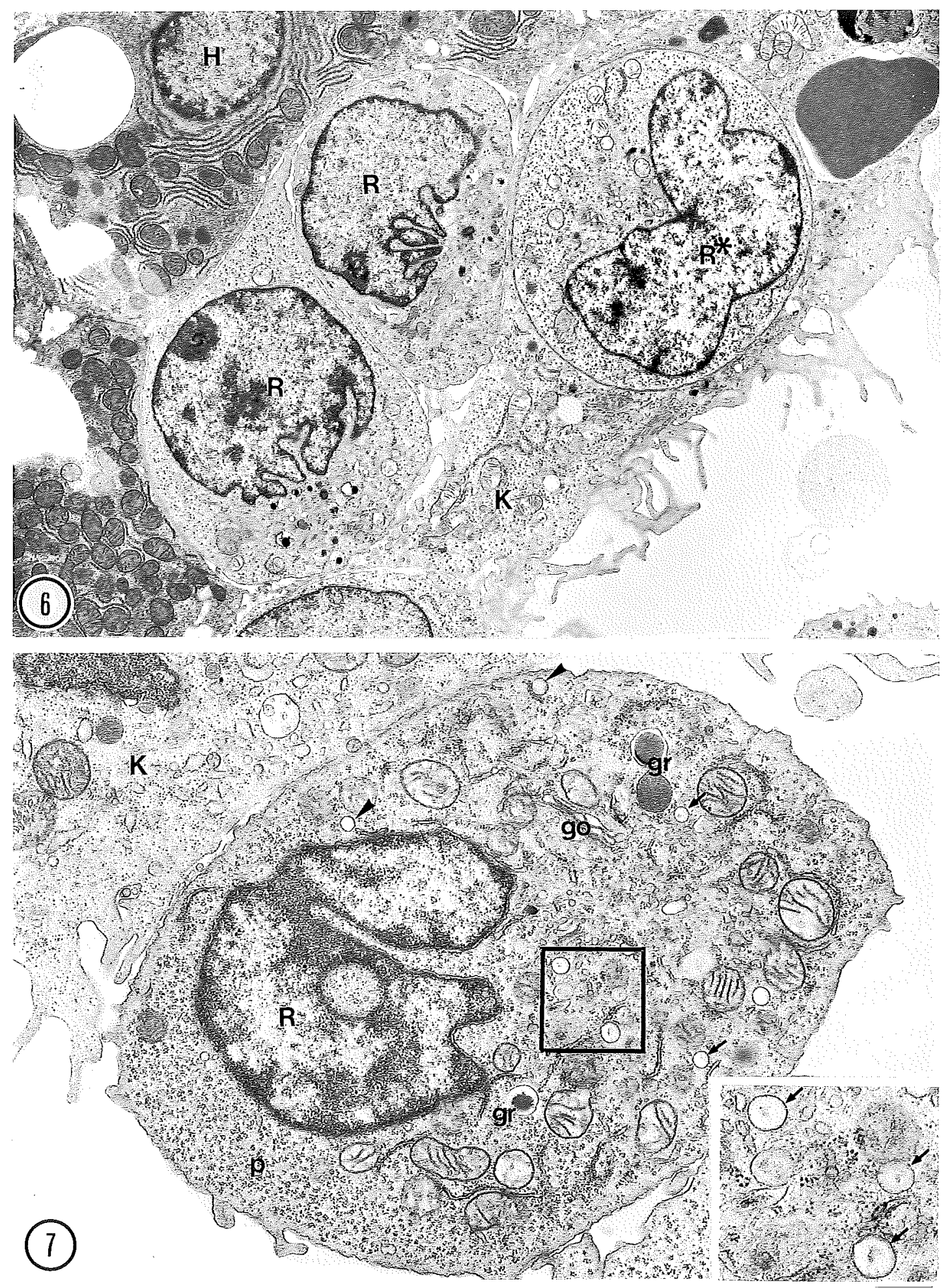

Fig. 6 Ultrastructure of RNK-16 cells (passage 7) that have metastasized to the liver 18 days after intraperitoneal injection. Two RNK cells $(R)$ exist in the space of Disse, attaching directly to the hepatocytes $(H)$. One RNK cell $\left(R^{*}\right)$ is phagocytized by a Kupffer cell $(K)$. They have irregular shaped nuclei and dense granules. $\times 5,000$

Fig. 7 In the RNK-16 cell $(R)$ which is adhered to a Kupffer cell $(K)$ via a wide contact surface, there are many RCV (arrows) and empty $0.2 \mu \mathrm{m}$ vesicles (arrowheads) as well as several dense granules ( $g r$ ). go, Golgi apparatuses; $p$, polysomes. $\times 13,000$; inset, $\times 29,000$ 
Table 3 Frequency of $0.2 \mu \mathrm{m}$ Vesicles and Dense Granules in RNK-16 Cells Which Have Metastasized to the Liver and Spleen, or Have Grown in the Peritoneum for 18 Days after Intraperitoneal Injection.

\begin{tabular}{ccccc}
\hline Tissue & \multicolumn{2}{c}{$0.2 \mu \mathrm{m}$ vesicles (number } \\
per cell transection $\pm \mathrm{SD})$ & $\begin{array}{c}\text { Frequency of RCV- } \\
\text { Total }\end{array}$ & $\begin{array}{c}\mathrm{RCV} \\
\text { containing RNK cells }\end{array}$ & $\begin{array}{c}\text { Dense granules } \\
\text { (number per cell } \\
\text { transection } \pm \mathrm{SD})\end{array}$ \\
\hline $\begin{array}{c}\text { Liver } \\
(\mathrm{n}=37 \text { cells })\end{array}$ & $8.1 \pm 4.2^{*}$ & $1.4 \pm 1.5^{*}$ & 65 & $5.7 \pm 2.9^{* *}$ \\
$\begin{array}{c}\text { Spleen } \\
(\mathrm{n}=35 \text { cells })\end{array}$ & $3.1 \pm 2.3$ & $0.5 \pm 0.8$ & 40 & $5.0 \pm 2.6$ \\
$\begin{array}{c}\text { Peritoneum } \\
(\mathrm{n}=49 \text { cells })\end{array}$ & $4.2 \pm 3.2$ & $0.7 \pm 0.8$ & 48 & $4.0 \pm 3.2$ \\
\hline
\end{tabular}

*Significantly greater than spleen or peritoneum, $P<0.01$. $* *$ Significantly greater than peritoneum, $P<0.05$

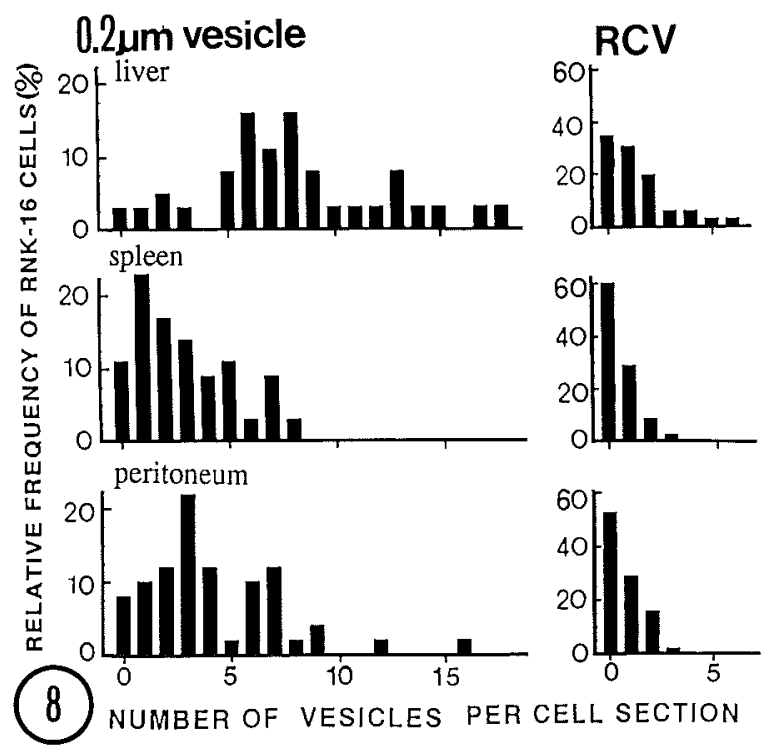

Fig. 8 Distribution of $0.2 \mu \mathrm{m}$ vesicles (empty $0.2 \mu \mathrm{m}$ vesicles $+\mathrm{RCV}$ ) and RCV in RNK-16 cells localized in various organs. The distribution of $0.2 \mu \mathrm{m}$ vesicle (left) and RCV (right) on sections of RNK-16 cells (passage 7) which have metastasized to the liver $(\mathbf{n}=37)$ and spleen $(\mathrm{n}=35) 18$ days after intraperitoneal injection were compared to RNK-16 cells (passage 8) $(n=49)$ obtained from the peritoneal cavity 14 days after intraperitoneal injection. The height of the bars indicates the percentage of RNK cells which have the specified number of $0.2 \mu \mathrm{m}$ or rod-cored vesicles on the section among the total RNK cells counted in each compartment.

acteristic to NK cells or cytotoxic T cells and indicate that granules of RNK cells derive from MVB.

The present study has revealed that RNK cells exhibit RCV, which is one of the most characteristic cell organelles of NK cells. The morphology of RCV was identical to that seen in normal NK cells. To date, RCV have been exclusively observed in NK cells and are therefore thought to be related to lineage-specific functions of NK cells. The fact that NK cells continue to possess RCV even after they have been transformed into leukemia (RNK) cells supports the idea that RCV, like MVB-related dense granules, are fundamental structures of $\mathrm{NK}$ cells.

The frequency of RCV differed between RNK11 and -16 cells. The fact that there was no numerical change of $0.2 \mu \mathrm{m}$ vesicles during the several intraperitoneal passages of RNK-11 cells indicates that the expression of RCV and empty $0.2 \mu \mathrm{m}$ vesicles may be determined genetically and the frequency is maintained constantly when incubated under the same condition.

We have revealed in a previous study that liver LGL contain a larger number of $0.2 \mu \mathrm{m}$ vesicles and RCV than splenic or peripheral blood LGL in the normal F344 rat, and speculated that the liver microenvironment may augment the expression of RCV in NK cells (5). We investigated here whether such up-regulation of RCV was seen also in RNK cells which metastasized and localized in the liver.

Two experiments of rapid and delayed metastasis of RNK cells have demonstrated that RNK cells exhibited a significantly increased number of RCV after they metastasized to the liver, in contrast to RNK cell metastases found in the spleen. These results indicate that the expression of RCV may be regulated by the microenvironment of the liver 

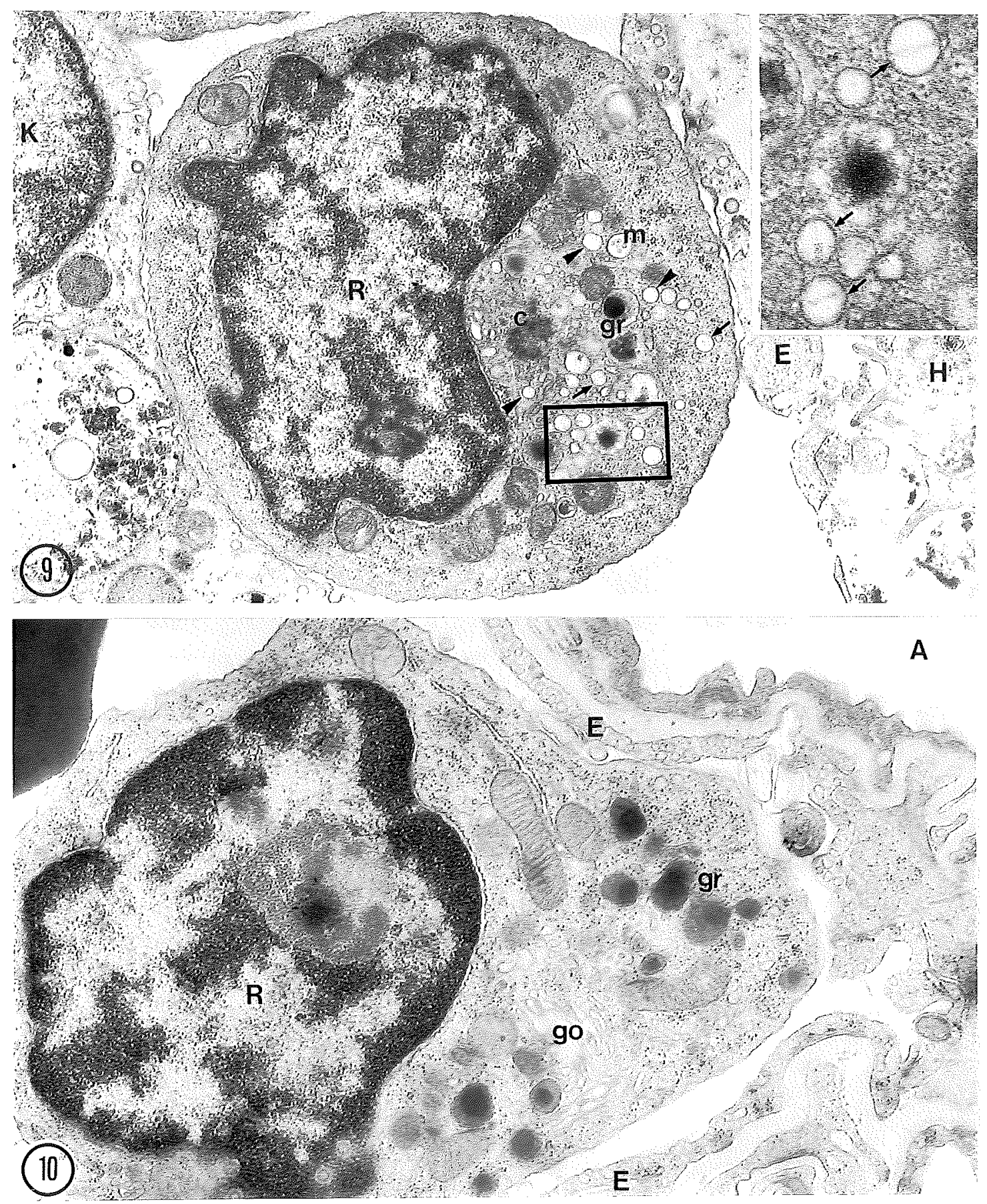

Figs. 9-12 Ultrastructure of RNK-0 cells (passage 3) which have metastasized to various organs at 3 months after intraperitoneal inoculation. Fig. 9: RNK-0 cells $(R)$ which have metastasized to the liver. They exist in the sinusoid adhering to sinusoidal endothelial cells $(E)$ and Kupffer cells $(K)$. They have many empty $0.2 \mu \mathrm{m}$ vesicles (arrowheads) and rod-cored vesicles (arrows). $H$, hepatocytes; $g r$, dense granules; $c$, centrioles; $m$, multivesicular bodies. $\times 15,000$; inset, $\times 43,000$

Fig. 10 RNK-0 cells $(R)$ which have metastasized to the lung. They exist in the pulmonary capillary. They contain many dense granules $(g r)$ but a few $0.2 \mu \mathrm{m}$ vesicles. $A$, pulmonary alveolus; $E$, endothelial cells of the capillary; go, Golgi apparatuses. $\times 15,000$ 

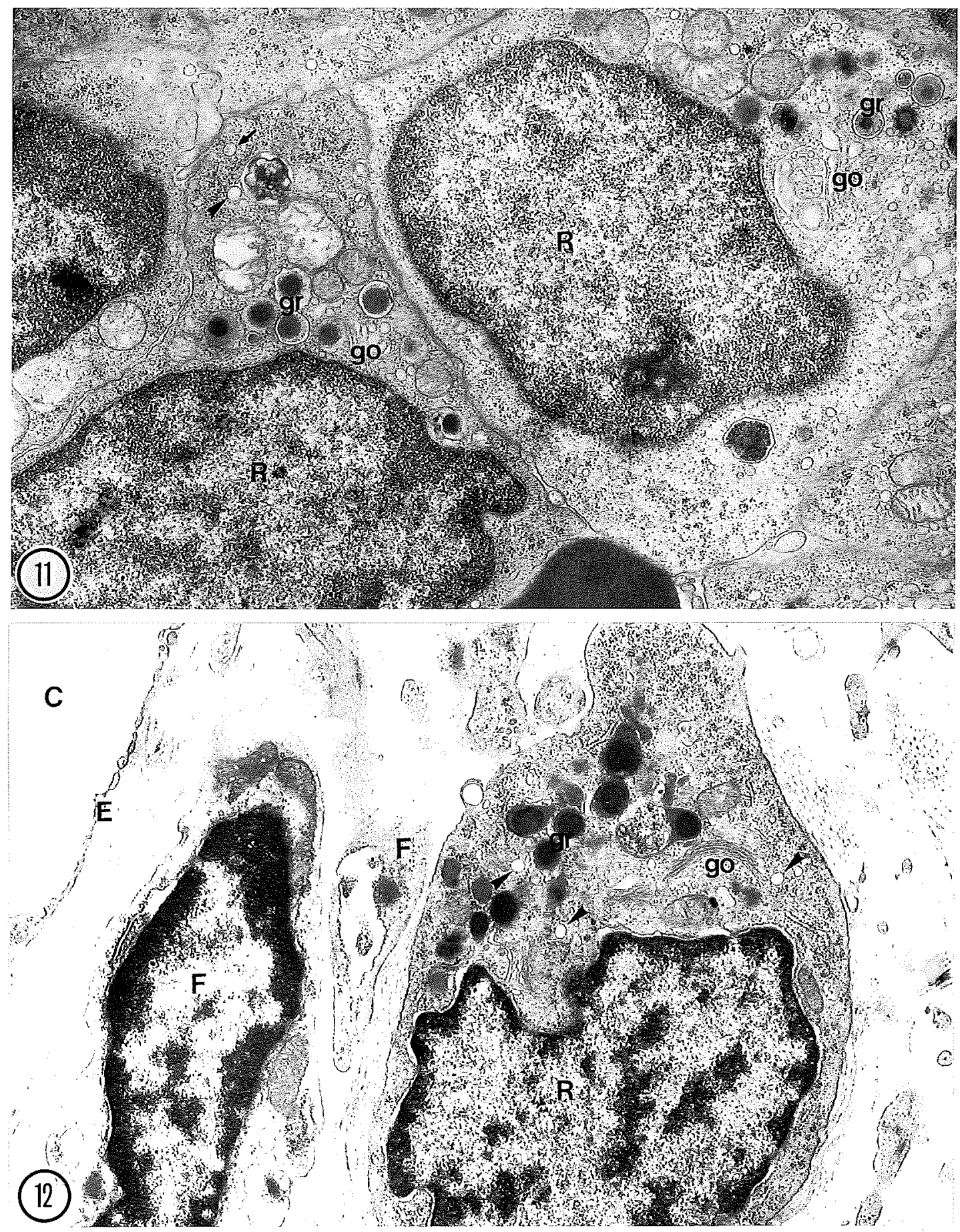

Fig. 11 RNK-0 cells $(R)$ which have metastasized to the red pulp of the spleen. They contain many dense granules $(g r)$ but a few empty $0.2 \mu \mathrm{m}$ vesicles (arrowheads) and RCV (arrow). go, Golgi apparatuses. $\times 15,000$

Fig. 12 RNK-0 cells $(R)$ which have metastasized to the kidney. An RNK cell is located in the connective tissue between epithelial cells of the tubule and peritubular capillaries $(C)$ and contains dense granules ( $g r$ ) and empty $0.2 \mu \mathrm{m}$ vesicles (arrowheads). F, fibroblasts; go, Golgi apparatuses. $\times 15,000$ 
Table 4 Frequency of $0.2 \mu \mathrm{m}$ Vesicles and Dense Granules in RNK-O Cells Which Have Metastasized to Various Organs by 3 Months after Intraperitoneal Injection

\begin{tabular}{ccccc}
\hline Tissue & $\begin{array}{c}0.2 \mu \mathrm{m} \text { vesicles (number } \\
\text { per cell transection } \pm \mathrm{SD})\end{array}$ & \begin{tabular}{c} 
Frequency of RCV- \\
containing RNK cells \\
\cline { 2 - 5 }
\end{tabular} & $\begin{array}{c}\text { Total } \\
\text { RCV }\end{array}$ & $\begin{array}{c}\text { Dense granules } \\
\text { (number per cell }\end{array}$ \\
$\begin{array}{c}\text { Liver } \\
\text { transection } \pm \text { SD) }\end{array}$ \\
$\begin{array}{c}\text { Spleen } \\
\quad(\mathrm{n}=60 \text { cells })\end{array}$ & $11.6 \pm 4.9^{*}$ & $2.1 \pm 1.6^{*}$ & 83 & $7.0 \pm 3.4$ \\
$\begin{array}{c}\text { Lung } \\
(\mathrm{n}=30 \text { cells })\end{array}$ & $4.9 \pm 4.0$ & $0.9 \pm 1.4$ & 27 & $6.6 \pm 2.6$ \\
$\begin{array}{c}\text { Kidney } \\
(\mathrm{n}=30 \text { cells })\end{array}$ & $1.1 \pm 1.3$ & $0.1 \pm 0.4$ & 10 & $6.5 \pm 2.0$ \\
$\begin{array}{c}\text { Lymph nodes } \\
(\mathrm{n}=30 \text { cells })\end{array}$ & $2.2 \pm 2.2$ & $0.5 \pm 0.8$ & 17 & $6.9 \pm 3.1$ \\
\hline
\end{tabular}

*Significantly greater than other organs, $P<0.01$. Data of liver and spleen RNK cells were obtained from two rats and those of other organs were from one rat.

sinusoids. Vanderkerken et al. (13) have reported morphological and functional differences between liver LGL and peripheral blood LGL. We also have previously reported that LGL in the liver of normal rats exhibit more $0.2 \mu \mathrm{m}$ vesicles and $\mathrm{RCV}$ than peripheral blood LGL and spleen LGL (5). The present results showing changes in RNK cells after metastasis to the liver are consistent with the previous data showing differences in normal LGL from various tissues. In fact, experiments using ${ }^{89} \mathrm{Sr}$ to selectively deplete bone marrow cells showed that the increase of NK cells in the liver by the administration of biological response modifiers (BRM) was due to rapid emigration from the bone marrow (15), suggesting that even newly emigrated LGL rapidly exhibit an increase in RCV after localizing in the liver. However, it is not yet clear whether there exist resident liver NK cells that regenerate and function locally or, whether all liver NK cells are generated from influx of peripheral blood NK cells and subsequent differentiation in the liver.

The present results using metastatic RNK leukemia cells, together with previous studies of normal NK cells $(5,11,13)$, indicate that the microenvironment of the liver sinusoids have the capacity to induce the maturation or differentiation of NK cells. Vanderkerken et al. (12) recently reported that Kupffer cells may play an important role in the differentiation of NK cells in the liver. The present results suggest that the RNK cell lines may be a valuable model for studying the regulation and function of the characteristic RCV in NK cells.

The authors express sincere thanks to Ms Eilene Gruys and Mr John W. Wine for their excellent technical support, and Ms Susan Charbonneau and Joyce Vincent for their secretorial and editorial assistance. We also express our appreciation to Dr Dan L. Longo, NCI-FCRDC, for his valuable advice. Dr Kenji Kaneda was supported during the course of these studies by a Fogarty International Research Fellowship.

Received 26 September 1995; and accepted 22 November 1995

\section{REFERENCES}

1. Bunkhardt J. K., Hester S., Lapham C. K. and Argon Y. (1990) The lytic granules of natural killer cells and dualfunction organelles combining secretory and pre-lysosomal compartments. J. Cell. Biol. 111, 2327-2340

2. DAN C., KANEdA K. and WAKE K. (1985) A striking increase in rod-cored vesicles in pit cells (natural killer cells) and augmentation of the liver-associated natural killer activity by a streptococcal preparation (OK-432). Biomedical Res. 6, 347-351

3. Henkart P. A., Millard P. J., Reynold C. W. and Henkart M. P. (1984) Cytolytic activity of purified cytoplasmic granules from cytotoxic rat large granular lymphocyte tumors. J. Exp. Med. 160, 75-93

4. Kaneda K., Kataoka M., Kishiye T., Yamamoto H. and WAKE K. (1991) The intracellular distribution of cell organelles in natural killer cells during the cytolysis of bound tumor cells, with special reference to the rod-cored vesicles. Arch. Histol. Cytol. 54, 69-79

5. Kaneda K., Pilaro A. M., Sayers T. J., Nagashima K., Gonda M. A., Ortaldo J. R. and Wiltrout R. H. (1994) Quantitative analysis of rod-cored vesicles and dense gran- 
ules of large granular lymphocytes in the rat liver, spleen and peripheral blood. Cell Tiss. Res. 276, 187-195

6. Kaneda K., Senoo H. and WaKe K. (1982) Rod-cored vesicles; a new type of vesicles in the pit cells. In Sinusoidal Liver Cells (ed. KNook D. L. and WISSE E.) Elsevier, Amsterdam, 77-84

7. KANEDA K. and WAKE K. (1983) Distribution and morphological characteristics of the pit cell of the rat. Cell Tiss. Res. 233, 485-505

8. Millard P. J., Henkart M. P., Reynold C. W. and Henkart P. A. (1984) Purification and properties of cytoplasmic granules from cytotoxic rat LGL tumors. $J$. Immunol. 132, 3197-3204

9. Reynolds C. W., Bere E. M. and Ward J. M. (1984) Natural killer activity in the rat. III. Characterization of transplantable large granular lymphocyte (LGL) leukemias in the F344 rat. J. Immmonol. 132, 534-540

10. Sayers T., Wiltrout T. A., Sowder R., Munger W. L., Smyth M. J. and Henderson L. E. (1992) Purification of a factor from the granules of a rat natural killer cell line (RNK) that reduces tumor cell growth and changes tumor morphology. Molecular identity with a granule serine protease (RNKP-1). J. Immunol. 148, 292-300

11. Vanderkerken K., Bouwens L., de Neve W., van den
Berg K., Baekeland M., Delems N. and Wisse E. (1992) Origin and differentiation of hepatic natural killer cells (pit cells). Hepatology 18, 919-925

12. Vanderkerken K., Bouwens L., van den Berg K., BaEKeland M. and Wisse E. (1995) The role of Kupffer cells in the differentiation process of hepatic natural killer cells. Hepatology 22, 283-290

13. Vanderkerken K., Bouwens L. and Wisse E. (1990) Characterization of phenotypically and functionally distinct subset of large granular lymphocytes (pit cells) in rat liver sinusoids. Hepatology 12, 70-75

14. Ward J. M. and ReYNolds C. W. (1983) Large granular lymphocyte leukemia. A heterogeneous lymphocytic leukemia in F344 rats. Amer. J. Pathol. 111, 1-10

15. Wiltrout R., Pilaro A. M., Gruys M. E., Talmadge J. E., Longo D. L., Ortaldo J. R. and Reynolds C. W. (1989) Augmentation of mouse liver-associated NK activity by biological response modifiers occurs largely via rapid recruitment of LGL from the bone marrow. J. Immunol. 143, 372-378

16. Wisse E., van't Noordende J. M., van der Meulen J. and DaEms W. Th. (1976) The pit cells: description of a new type of cell occurring in rat liver sinusoids and peripheral blood. Cell Tiss. Res. 173, 423-435 